\title{
Comparison of Constitutive Flow Curve Relations in Cold and Hot Forming
}

\author{
L.W. Meyer, A. Weise and F. Hahn
}

Technische Universität Chemnitz-Zwickau, Facultät für Maschinenbau und Verfahrenstechnik, Lehrstuhl Werkstoffe des Maschinenbaus 24300, 09107 Chemnitz, Germany

\begin{abstract}
Based on experimental results of upsetting tests of an case hardening steel, constitutive stress-strain relations were developed according to various phenomenological and semiempirical models proposed in the literature, covering the strain rate between $\dot{\varphi}=10^{-2}$ to $10^{1} \mathrm{~s}^{-1}$ and the temperature range between room temperature and $1200^{\circ} \mathrm{C}$ including, with special emphasis, the two phase region between $A_{1}$ and $A_{3}$.

Résumé. Sur la base des résultats des tests de compression d'un acier de cémentation, des équations constitutivées ont été développées correspondant aux modèles d'équations constitutives divers proposés de la littérature. Les études réalisées comprendraient des vitesses de dilatation de $10^{-2}$ à $10^{1} \mathrm{~s}^{-1}$ et des températures entre la température ambiante et $1200^{\circ} \mathrm{C}$ en considération spéciale de la domaine diphasique de $\mathrm{A}_{1}$ à $\mathrm{A}_{3}$.
\end{abstract}

\section{Introduction}

Within the last years mathematical simulations in forming became an essential tool to optimise even complicated forming processes. Apart from the correct description of tribological and thermal boundary conditions the experimental determination and the mathematical formulation of stress-strain curves are of decisive importance for the accuracy of such calculations.

Based on the experimental results of compression tests, constitutive stress-strain relations were developed according to various phenomenological and semiempirical models proposed in the literature, covering the whole temperature range investigated including the two phase region between $A_{1}$ and $A_{3}$. To provide flow curve models for computer simulations of cold and hot forming processes, these models have to be able to describe the influence of metallurgical processes like strain hardening and dynamical softening on flow stress. The accuracy of the different models has been assessed by statistical methods.

\section{2}

Testing techniques

Flow curves of the case hardening steel $20 \mathrm{MoCrS} 4$ were measured in uniaxial hot compression tests with an high speed servohydraulic testing machine at constant rates of strain from $0,01 \mathrm{~s}^{-1}$ up to $10 \mathrm{~s}^{-1}$ in the temperature range between room temperature and $A_{3}$. Specimens with $10 \mathrm{~mm}$ in diameter and $15 \mathrm{~mm}$ high in Rastegaev-geometry were used in the tests., lubricants were chosen according the specific forming temperature. Up to a temperature of $500^{\circ} \mathrm{C}$, a special high temperature paste Nomynol VI $200-\mathrm{BFTM}^{\mathrm{TM}}$ and above $500^{\circ} \mathrm{C}$, various glass powders were used according to the deformation temperature, in order to avoid bulging and to ensure a quasi-uni-axial stress state.

The specimens were heated inside a special induction coil, which enables also to quench the specimen by an gas shower immediately after testing in order to freeze the structure for subsequent metallographic investigations. All specimens used had a normalised initial structure of ferrite and pearlite with an average grain diameter of ferrite of $8 \mu \mathrm{m}$.

Additional upsetting tests were carried out in the two phase $\alpha / \gamma$ region between $A_{1}$ and $A_{3}$ and in the temperature range of stable austenite up to $1200^{\circ} \mathrm{C}$ at constant rates of strain between $0,01 \mathrm{~s}^{-1}$ and $1 \mathrm{~s}^{-1}$ using a deformation dilatometer. Fig. 1 shows the experimental setup. The dilatometry specimens were of cylindrical shape with $5 \mathrm{~mm}$ in diameter and $10 \mathrm{~mm}$ high.

Article published online by EDP Sciences and available at http://dx.doi.org/10.1051/jp4:1997305 


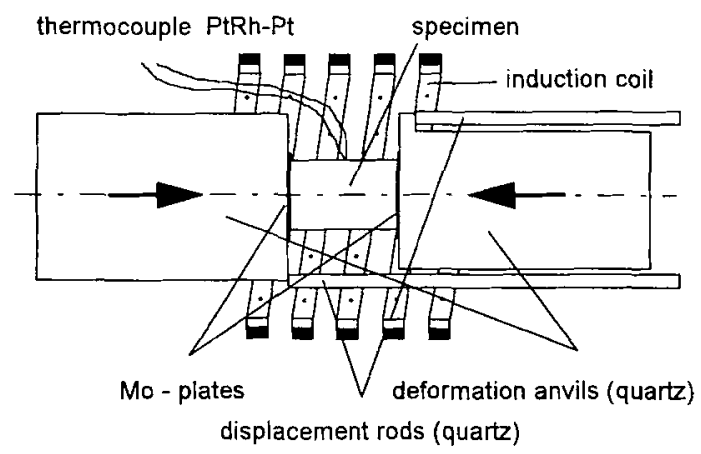

Figure 1: Testing setup of the deformation dilatometer

\section{Constitutive flow curve relations}

Table 1 contains an overview of some phenomenological and semiempirical flow-curve models proposed in the literature [1-5]. These models have been evaluated in respect of their suitability and accuracy to describe the stress strain curves in simulations of cold- , warm and hot forming processes. The empirical mathematical

Table 1: Constitutive flow-curve relations considered to evaluate their accuracy

\begin{tabular}{|c|c|c|}
\hline \multicolumn{2}{|l|}{ Flow curve equation } & Reference \\
\hline $\mathrm{k}_{\mathrm{f}}=\mathrm{A}_{0} \cdot \varphi^{\mathrm{a}_{1}} \cdot \dot{\varphi}^{\mathrm{a}_{2}} \cdot \exp \left(-\mathrm{a}_{3} \cdot \mathrm{T}\right)$ & (1) & $\begin{array}{c}\text { Hodgson [1] } \\
\text { Hajduk [2] }\end{array}$ \\
\hline $\mathrm{k}_{\mathrm{f}}=\mathrm{A}_{0} \cdot \varphi^{\mathrm{a}_{1}} \cdot \exp \left(\mathrm{a}_{4} \cdot \varphi\right) \cdot \dot{\varphi}^{\mathrm{a}_{2}} \cdot \exp \left(-\mathrm{a}_{3} \cdot \mathrm{T}\right)$ & (2) & Spittel, Hensel [3] \\
\hline $\mathrm{k}_{\mathrm{f}}=\mathrm{A}_{0} \cdot \varphi^{\mathrm{a}_{1}} \cdot \exp \left(\frac{\mathrm{a}_{4}}{\varphi}\right) \cdot \dot{\varphi}^{\mathrm{a}_{2}} \cdot \exp \left(-\mathrm{a}_{3} \cdot \mathrm{T}\right)$ & (3) & Spittel, Hensel [3] \\
\hline $\begin{array}{c}\mathrm{k}_{\mathrm{f}}=\mathrm{k}_{\mathrm{f} \max } \cdot\left\{\frac{\varphi}{\varphi_{\max }} \cdot \exp \left(1-\frac{\varphi}{\varphi_{\max }}\right)\right\}^{\mathrm{c}} \\
\mathrm{Z}=\dot{\varphi} \cdot \exp \left(\frac{Q_{\mathrm{d}}}{\mathrm{R} \cdot \mathrm{T}}\right)=\mathrm{f}\left(\mathrm{k}_{\mathrm{f} \max }\right)=\mathrm{A} \cdot \sinh \left(\beta \cdot \mathrm{k}_{\mathrm{f} \max }\right)^{\mathrm{n}} \\
\varphi_{\max }=\mathrm{b}_{0} \cdot \mathrm{d}_{0} \mathrm{~b}_{1} \cdot \mathrm{Z}^{\mathrm{b}_{2}}\end{array}$ & (4) & Cingara [4] \\
\hline $\begin{array}{l}k_{f}=k_{f m s}-\left(k_{f m s}-k_{f 0}\right) \cdot \exp (b \cdot \varphi)-\left(k_{f m s}-k_{f s}\right) \cdot X_{d y n} \\
X_{d y n}= \begin{cases}0 & \varphi<\varphi_{c} \\
1-\exp \left[-2,996 \cdot\left(\frac{\varphi-\varphi_{c}}{\varphi_{s}-\varphi_{c}}\right)^{2}\right] ; & \varphi \geq \varphi_{c}\end{cases} \end{array}$ & (5) & Voce [5] \\
\hline $\begin{array}{ll}k_{f 0}=c_{0} \cdot d_{0} c_{1} \cdot z^{c_{2}} & \\
k_{f m s}=d_{0} \cdot \arcsin h\left(\frac{z^{d_{1}}}{d_{2}}\right) ; \quad k_{f s}=e_{0} \cdot \operatorname{arcsinh}\left(\frac{z^{e_{1}}}{e_{2}}\right) \\
\varphi_{c}=f_{0} \cdot d_{0} f_{1} \cdot z^{f_{2}} \quad ; \quad \varphi_{s}=g_{0} \cdot d_{0} g_{l} \cdot z^{g_{2}}\end{array}$ & & \\
\hline
\end{tabular}


equations (1) to (3) in table 1 allow to describe the flow stress in dependance of the forming parameters strain, strain rate and temperature. Modifications of eq. (1) have been introduced by Hensel and Spittel [3] in eq. (2) and (3) to take the influence of dynamic softening processes on flow stress into account

Models (4) and (5) assume that hot forming is a thermally activated process. Under that assumption, the flow stress can be expressed in terms of the Zener-Hollomon Parameter $Z$, describing the combined influence of strain rate and temperature by means of an Arrhenius function. The influence of the initial grain size as a parameter of structure can be taken into account by empirical equations describing the characteristic strains for the onset of dynamic recrystallisation $\varphi_{c}$, the strain $\varphi_{\max }$ at which the flow stress reaches his maximum value $k_{f \max }$ and the strain $\varphi_{\mathrm{s}}$ at which the flow stress reaches the steady state value $k_{\mathbb{f s}}$. The occurence of these characteristic points in flow curves of steels in the austenitic range is attributed to dynamic recrystallisation. In its simple form, equation (4) is only valid up to strains of the order of $\varphi_{\max }$. Equation (5) for the flow stress consists of two terms, whereby the first one describes the strain hardening, first proposed by Voce [5], and the second describes softening by dynamic recrystallisation. This is the only model in table 1 that involves a semiempirical formulation by means of an Avrami function of the dynamically recrystallized volume fraction $X_{d y n}$. Therefore model (5) is suitable to take into account either for the strain hardening and for dynamic softening occuring under hot forming conditions

\section{$4 \quad$ Results}

\subsection{Temperature range of stable Austenite}

Experimentally measured flow curves from hot-compression tests have been used to determine the constants of the flow curve equations (1) to (3) by regression analysis. To obtain the apparent activation energy for hot forming in eq. (4) and (5), regression analysis can be applied by plotting $\ln \sinh \left(\beta \cdot \mathrm{k}_{\mathrm{fmax}}\right)$ of the stress-strain curve field versus $\ln \dot{\varphi}$ and $1 / \mathrm{T}$. Variation can be used to determine the $\beta$-value at which the gradient dispersion is minimized. Thus the maximum flow stress $\mathrm{k}_{\mathrm{fmax}}$ can be expressed in terms of the Zener-Hollomon parameter $Z$. The strain hardening coefficient $\mathrm{c}$ in eq. (4) is obtained for each stress-strain curve from the slope of a plot of $\ln \left(k_{\mathrm{f}} / \mathrm{k}_{\mathrm{fmax}}\right)$ versus $\left(1-\varphi / \varphi_{\max }+\ln \left(\varphi / \varphi_{\max }\right)\right)$. The constants for the equation describing the logarithmic strain at which the flow stress maximum occurs in model (4) are to determine empirically from regression analysis of experimental data. The determination of the constants in Flow-curve model (5) are to determine in

Table 2: Material constants and coefficients determined from measured flow curves according to the flow curve equations in table 1 for the temperature range of stable austenite of steel grade $20 \mathrm{MoCrS} 4$

\begin{tabular}{|c|c|c|c|c|}
\hline \multicolumn{5}{|c|}{ Flow curve equation type according to table 1} \\
\hline (1) & (2) & (3) & (4) & (5) \\
\hline $\begin{array}{l}\mathrm{A} 0=20723 \\
\mathrm{a} 1=0,1332 \\
\mathrm{a} 2=0,1554 \\
\mathrm{a} 3=0,003857\end{array}$ & $\begin{array}{l}\mathrm{A}_{0}=29495 \\
\mathrm{a}_{1}=0,2308 \\
\mathrm{a}_{2}=0,1516 \\
\mathrm{a}_{3}=0,00385 \\
\mathrm{a}_{4}=-0,6275\end{array}$ & $\begin{array}{l}A_{0}=19205 \\
a_{1}=0,0643 \\
a_{2}=0,1532 \\
a_{3}=0,00385 \\
a_{4}=-0,0037\end{array}$ & $\begin{array}{l}c=0,289 \\
Q_{d}=332600 \mathrm{~J} / \mathrm{mol} \\
A=3,8964 * 10^{12} \\
\beta=0,00868 \\
n=4,927 \\
b_{0}=0,002182 \\
b_{1}=0,196 \\
b_{2}=0,1436\end{array}$ & $\begin{array}{l}b=-14,5 \\
c_{0}=6,9578 \\
c_{1}=-0,254 \\
c_{2}=0,09516 \\
d_{0}=117,65 \\
d_{1}=0,1971 \\
d_{2}=310,7 \\
e_{0}=115,2 \\
e_{1}=0,2068 \\
e_{2}=477,5 \\
f_{0}=0,001746 \\
f_{1}=0,196 \\
f_{2}=0.1436 \\
g_{0}=0,000888 \\
g_{1}=0.285 \\
g_{2}=0.193\end{array}$ \\
\hline
\end{tabular}


an adequate way.

Table 2 contains all constants of the different flow curve equations obtained from experimental stress-strain curves in this way. An assesment of the accuracy of the mathematical descibtion of experimental stress strain curves can be perfomed by plotting the cumulative frequency versus the relative error in figure 2 . When applying eq.(1) to (3) to calculate stress-strain curves in the temperature range of stable austenite the relative error is about $15 \%$ assuming an error probability of $80 \%$. As can be seen from figure 2 , the modifications introduced by [3] to take into account dynamic softening processes cause only little effects on the agreement between measured and calculated stress-strain curves. When introducing the influence of initial structure on the

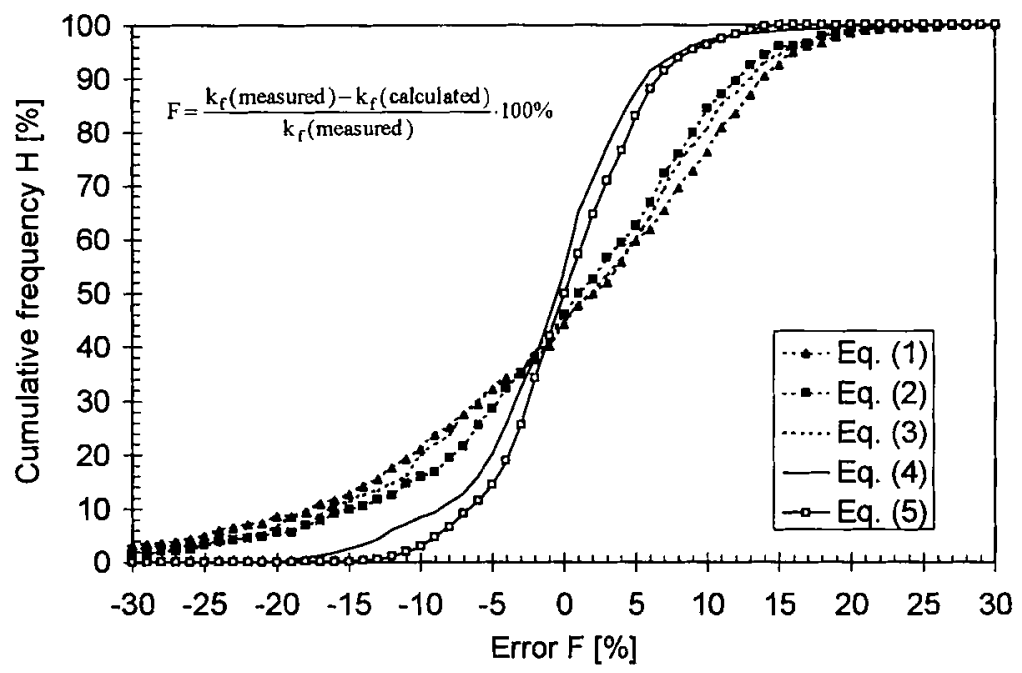

Figure 2: Cumulative frequency of the relative error when applying eq. (1) to (5) for calculating stress-strain curves of steel grade $20 \mathrm{MoCrS} 4$ in the temperature range of stable austenite
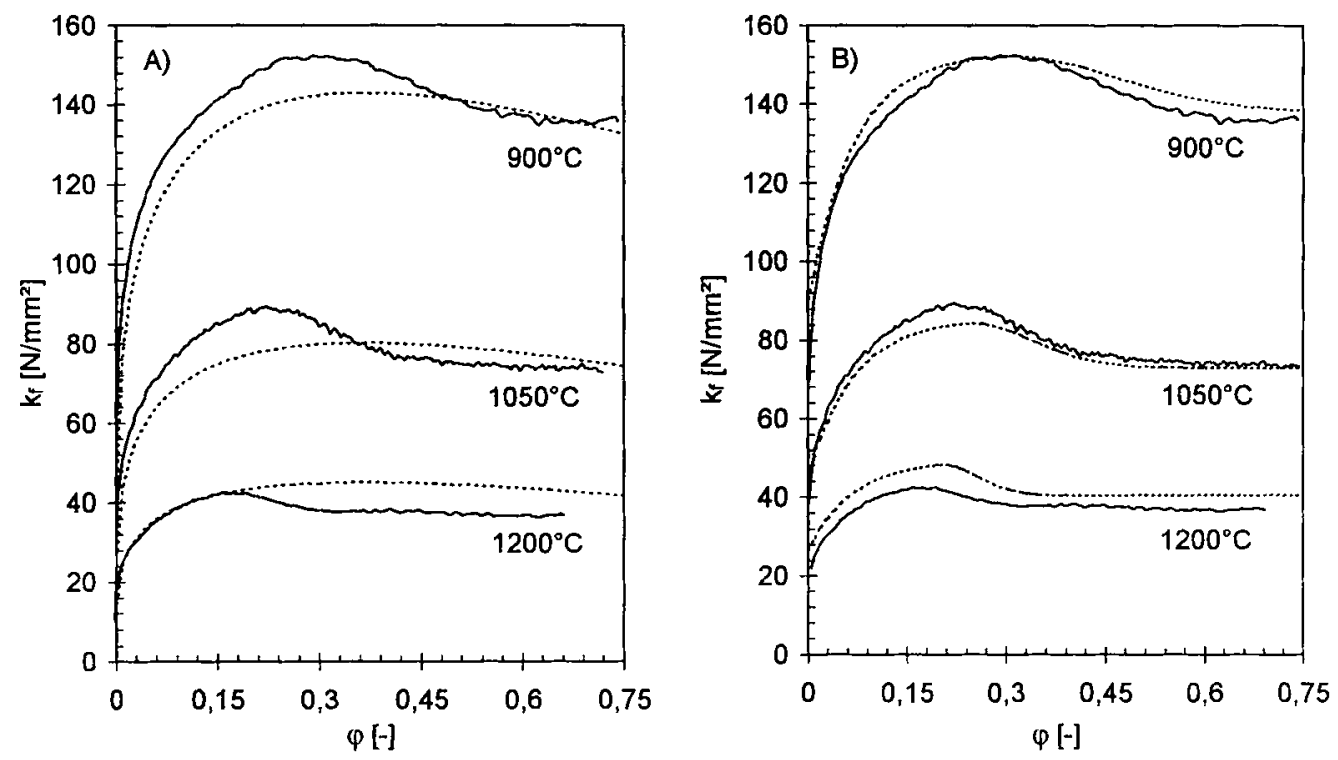

Figure 3: Comparision between measured stress-strain curves (solid lines) and calculated stress-strain curves (dotted lines) for different tomperatures and a constant strain rate of $0,1 \mathrm{~s}^{-1}$; A) calculated according to eq. (2); B) calculated according to eq. (5) 
shape of the stress-strain curves into the mathematical flow curve formulation, as done by eq. (4) an (5), the agreement between measured and calculated flow stress can be improved considerably. The relative error can be decreased to the order of $7 \%$, whereby eq. (4) is only valid up to $\varphi_{\max }$. When applying eq. (5) the best agreement between measured and calculated stress strain curves including the steady state range is obtained. This is due to the implementation of dynamic recrystallisation into the flow curve equation. For example, figure 3 compares measured stress strain curves with calculated curves, according eq. (2) and (5).
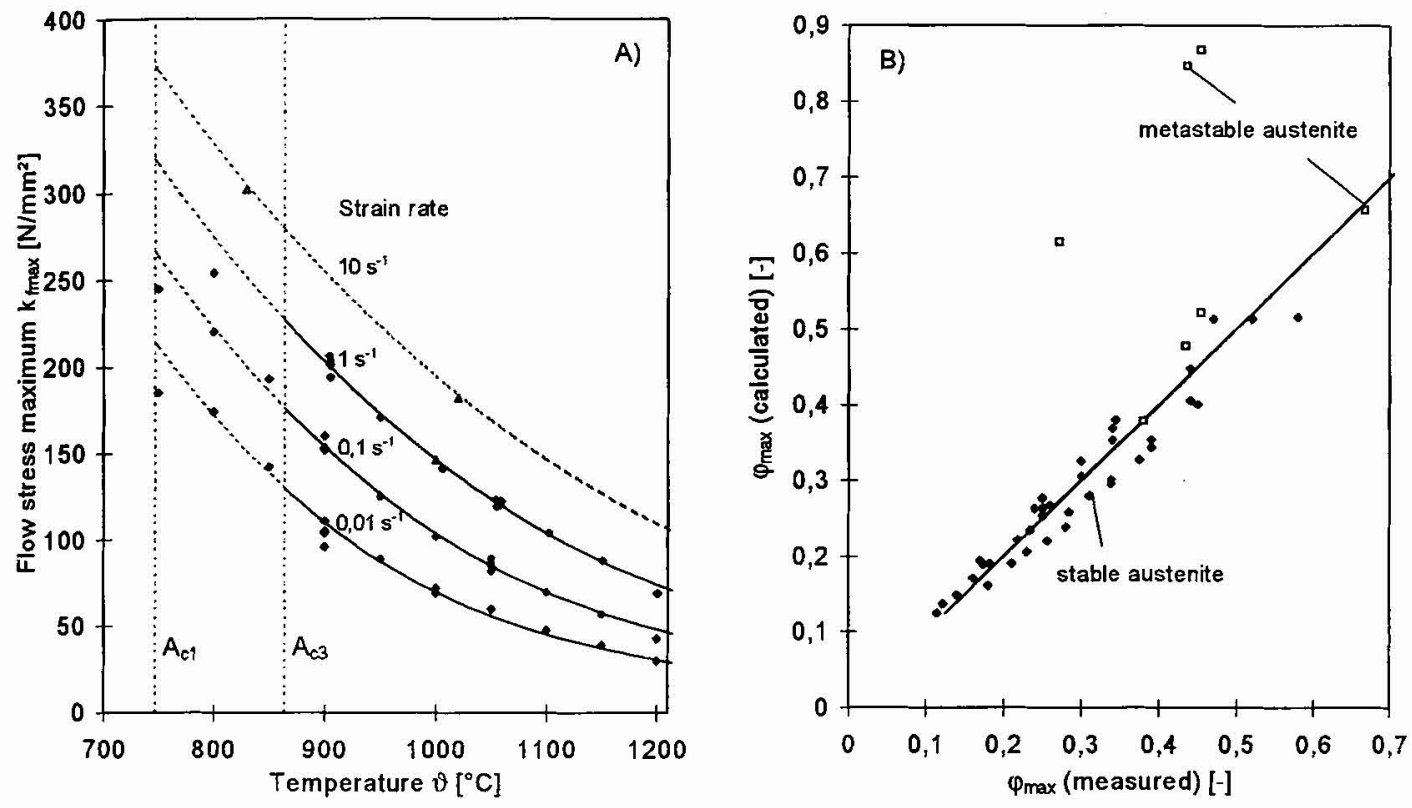

Figure 4: A) Comparision between measured and calculated flow stress maximum $\mathrm{k}_{\text {fnax }}$ versus temperature; B) comparision between measured and calculated strain at flow stress maximum $\varphi_{\text {max }}$

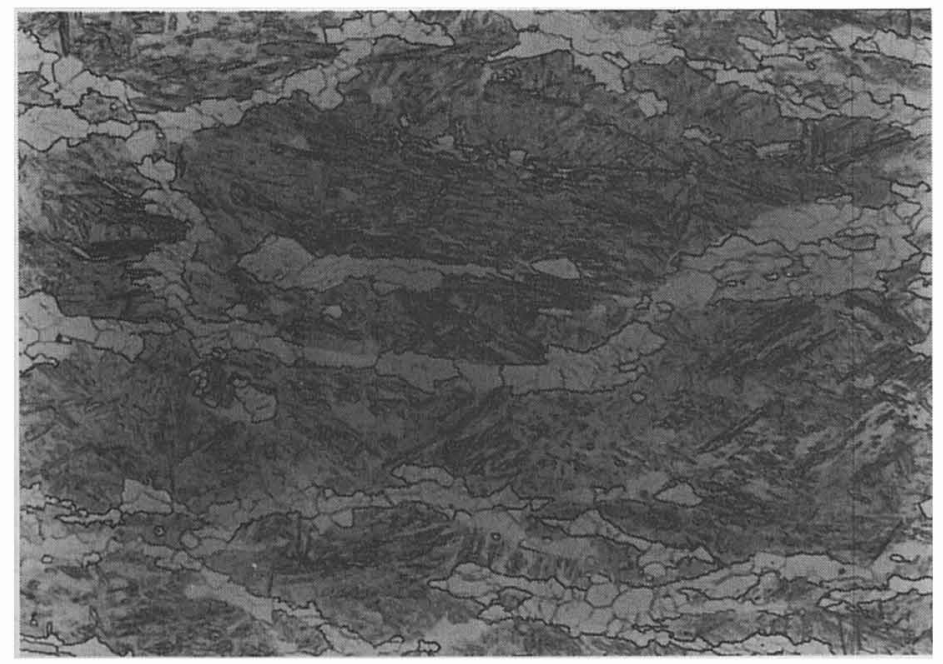

$25 \mu \mathrm{m}$

Figure 5: Ferrite along the former grain bounderics of deformed austenite of stecl grade 20MoCrS4. transformed from metstable austenitc during deformation at $7500^{\circ} \mathrm{C}$ after atustenitiation at $10500^{\circ} \mathrm{C}$. 
Provided that no partial $\gamma / \alpha$ - transformation takes place before or during the deformation, eq. (4) and (5) can be used to calculate stress strain curves of the metastable austenite in the temperature range between $A_{1}$ and $A_{3}$, as has been proved in additional compression tests. This can be seen from the results in figure 4 A) and $B)$. The significant differences between some measured values and the calculated curves in the temperature range between $A_{1}$ and $A_{3}$ is caused by a partial $\gamma / \alpha$ - transformation that is enhanced by the plastic deformation. Metallographic observations of these specimens revealed ferrite along the grain bounderies of the deformed former austenite grains (see figure 5).

\subsection{Two phase region between $\mathrm{A}_{1}$ and $\mathrm{A}_{3}$}

In the two phase $\alpha / \gamma$-region the maximum flow stress $\mathrm{k}_{\text {fmax }}$ can not expressed in terms of the Zener-Hollomon parameter in the same good agreement as indicated in figure $4 \mathrm{~A}$. Beside that, no significiant dependency has been found between characteristic strains like $\varphi_{\max }$ and volume fraction of ferrite, grain size, temperature and strain rate. Thus, a mathematical formulation of stress-strain curves in the two phase $\alpha / \gamma$-region according to eq. (4) and (5) can not be applied in that simple form used to describe the behaviour of stable austenite. This is attributed to possible deformation- and/or stress-induced phase transformations and related effects, like transformation plasticity, occuring during deformation. A complete formulation of the stress-strain behaviour in the two-phase region has to include these effects. Under the premise of applying these constitutive flowcurve relations in finite element simulations of forming processes, the calculation effort necessary for an complete description seems not to be justificated. From that point of view, the empirical stress-strain relation (2) has been chosen to express the flow stress as an state variable dependent on strain, strain rate and temperature without considering any structural effects, occuring during deformation. Table 3 contains the coefficients, determined by regression analysis according to eq. (2) from measured flow curves. Figure 6 shows calculated stress strain curves in comparision to measured curves in the two-phase $\alpha / \gamma$-region. Assuming an error probability of $80 \%$, the application of eq. (2) for calculating stress-strain curves in the temperature

Flow curve equation type (2) for application in the two phase $\alpha / \gamma$-region

\begin{tabular}{|c|c|}
\hline $\mathrm{A}_{0}$ & 2034 \\
$\mathrm{a}_{1}$ & 0,2024 \\
$\mathrm{a}_{2}$ & 0,0927 \\
$\mathrm{a}_{3}$ & $-0,001644$ \\
$\mathrm{a}_{4}$ & $-0,4647$ \\
\hline
\end{tabular}

Table 3: Coefficients determined from measured flow curves according to flow curve equation (2) in table 1 for the temperature range between $A_{1}$ and $A_{3}$ of steel grade $20 \mathrm{MoCrS} 4$

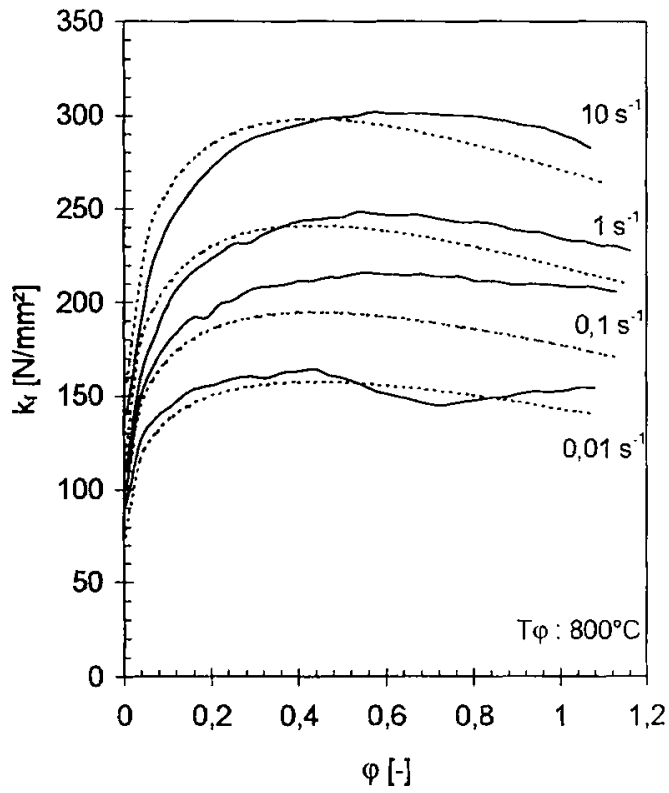

Figure 6: Measured (solid lines) and calculated stress-strain curves according to table 3 in the two phase $\alpha / \gamma$-region 
range between $A_{1}$ and $A_{3}$ causes an relative error of $11 \%$. Eq. (2) with the determined coefficients enables therefore a satisfactoring describtion of stress strain-curves in the two phase $\alpha / \gamma$-region.

\subsection{Temperature range below $A_{1}$}

Deformation induced segregations at temperatures between $100^{\circ} \mathrm{C}$ and $400^{\circ} \mathrm{C}$ and the spheroidisation of cementite at temperatures above $600^{\circ} \mathrm{C}$, which is enhanced by deformation, exclude the application of the flow curve models (4) and (5) assuming forming as an thermally activated process. As a first approach, again regression analysis of a measured stress-strain curve field in the temperature range up to $A_{1}$ has been performed according to eq. (3). Table 4 contains the coefficients determined empirically. In figure 7 can be seen, that the empirical formulation gives a reasonable agreement between measured and calculated flow stress up to $400^{\circ} \mathrm{C}$. Significiant differences at strains above 0,2 of the stress-strain curve at $600^{\circ} \mathrm{C}$ are attributed to the spheroidisation of cementite, which is enhanced by deformation. Assuming a probability of error of $80 \%$, the relative error in applying eq. (3) for predicting stress-strain curves up to $A_{1}$ is $12 \%$.

The premise that the flow stress is influenced by temperature, strain and strain rate in a mutually exclusive way, on which eq. (1) to (3) is based, is not fulfilled over the whole temperature range due to occuring structural changes like segragation and spheroidisation of cementite. On the other hand, the necessary effort of implementing all these structural changes in constitutive flow-curve equations can not be justified with the aim of applying these relations in finite element modelling of forming processes on an continuum level. For simulation of the microstructural development it is necessary to include occuring structural changes in the formulation.

Flow curve equation type (3) for application in the range between room temperature and $A_{1}$

\begin{tabular}{|c|c|}
\hline$A_{0}$ & 1066 \\
$a_{1}$ & 0,102 \\
$a_{2}$ & 0,0007 \\
$a_{3}$ & $-0,0006$ \\
$a_{4}$ & $-0,005$ \\
\hline
\end{tabular}

Table 4: Coefficients determined from measured flow curves according to flow curve equation (2) in table 1 for the temperature range between $20^{\circ} \mathrm{C}$ and $\mathrm{A}_{1}$ of steel grade $20 \mathrm{MoCrS} 4$

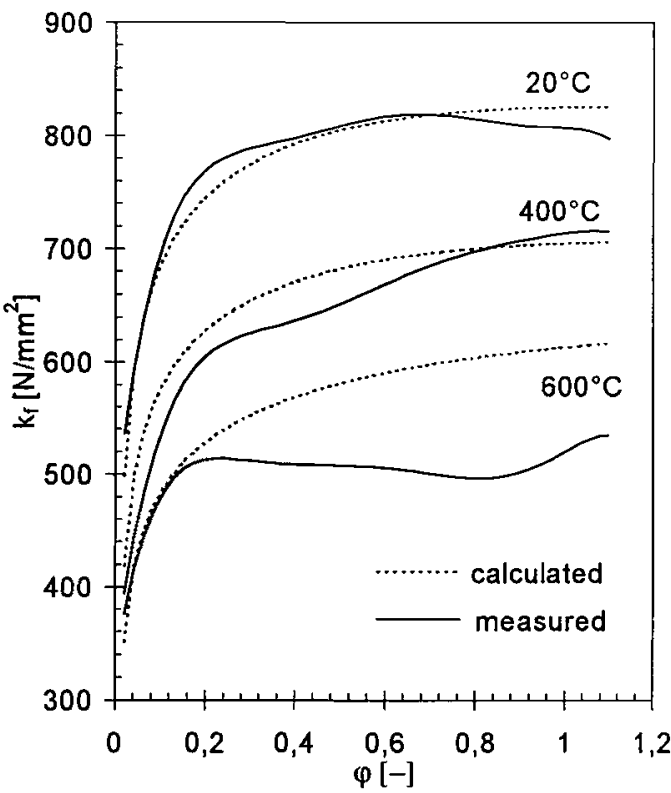

Figure 7: Measured (solid lines) and calculated stress-strain curves according to table 4 at temperatures below $A_{1}$ tested with constant strain rate of $10 \mathrm{~s}^{-1}$

\section{$5 \quad$ Summary}

Within the temperature range of stable austenite stress strain curves can be formulated mathematically in good quality using models, which assume hot forming to be a thermally activated process. These models can be 
extrapolated in the temperature range below $A_{3}$, provided that no partial $\gamma-\alpha$ transformation occurs before or during forming.

Due to structural changes during forming in the $\alpha / \gamma$-region and at temperatures below $\mathrm{A}_{1}$ the principle of regarding plastic deformation as an thermally activated process can not be employed in the same quality. An approach on the base of metal physics has to include structural changes occuring during deformation and their influence on flow stress.

The flow stress in the $\alpha / \gamma$-region and at temperatures below $A_{1}$ can be described in reasonable agreement with measured stress-strain curves by empirical equations.

\section{References}

[1] Hodgson; P. D.; Szalla, J. A.; Campell, P. J., Proc. of 4th Int. Steel Rolling Conf., Deauville 1987, France, Vol. 1, pp. c.8.1 - c.8.13

[2] Hajduk, M. et al., Hutnicke listy 27(1972), pp. 567 - 571

[3] Hensel, A.; Spittel, T., Kraft- und Arbeitsbedarf bildsamer Formgebungsverfahren (VEB Deutscher Verlag für Grundstoffindustrie, Leipzig 1978)

[4] Cingara, A.; McQueen, H.J., J. Mat. Proc. Techn. 36(1992) pp. 31 - 42

[5] Voce, E., J. Inst. Metals 74(1948) pp. $537-562$ 